\title{
Dihydroceramide Desaturase Inhibition by a Cyclopropanated Dihydroceramide Analog in Cultured Keratinocytes
}

\author{
Susanne Brodesser ${ }^{1}$ and Thomas Kolter ${ }^{2}$ \\ ${ }^{1}$ CECAD Cologne Platform Lipidomics, Institute for Medical Microbiology, Immunology and Hygiene, \\ University of Cologne, Goldenfelsstraße 19-21, 50935 Cologne, Germany \\ ${ }^{2}$ LIMES Program Unit Membrane Biology and Lipid Biochemistry, Kekulé Institute of Organic Chemistry and Biochemistry, \\ University of Bonn, Gerhard-Domagk-Straße 1, 53121 Bonn, Germany \\ Correspondence should be addressed to Thomas Kolter, tkolter@uni-bonn.de
}

Received 1 July 2010; Revised 21 September 2010; Accepted 27 October 2010

Academic Editor: Michel Lagarde

Copyright ( ) 2011 S. Brodesser and T. Kolter. This is an open access article distributed under the Creative Commons Attribution License, which permits unrestricted use, distribution, and reproduction in any medium, provided the original work is properly cited.

\begin{abstract}
Most mammalian sphingolipids contain a 4,5-(E)-double bond. We report on the chemical synthesis of a dihydroceramide derivative that prevents the introduction of the double bond into sphingolipids. Minimal alteration of the parent structure by formally replacing the hydrogen atoms in the 5- and in the 6-position of the sphinganine backbone by a methylene group leads to an inhibitor of dihydroceramide desaturase in cultured cells. In the presence of 10-50 $\mu \mathrm{M}$ of compound (1), levels of biosynthetically formed dihydroceramide and — surprisingly—also of phytoceramide are elevated at the expense of ceramide. The cells respond to the lack of unsaturated sphingolipids by an elevation of mRNAs of enzymes required for sphingosine formation. At the same time, the analysis of proliferation and differentiation markers indicates that the sphingolipid double bond is required to keep the cells in a differentiated state.
\end{abstract}

\section{Introduction}

Most mammalian sphingolipids contain an $(E)$-configured double bond between the carbon atoms $\mathrm{C} 4$ and $\mathrm{C} 5$ of the sphingoid moiety [1-3]. This structural element is introduced during the last step of ceramide biosynthesis by the enzyme dihydroceramide desaturase (DES1; Scheme 1), a protein bound to the membrane of the Endoplasmic Reticulum [4-7], encoded by the DEGS1 (degenerative spermatocyte homolog 1) gene, and myristoylated at its $N$-terminus [8]. While the mouse Des2 protein seems to have dihydroceramide $\Delta 4$-desaturase and 4-hydroxylase activity, the human homolog DES2 appears to be only a 4-hydroxylase [9]. The first and rate-determining step of the dihydroceramide desaturase-catalyzed reaction is the homolytic cleavage of the $\mathrm{C}-\mathrm{H}$-bond at $\mathrm{C}-4$ of the sphinganine backbone by a non-heme oxo-diiron species [10]. The function of the double bond within the sphingolipids is not entirely known. Experiments, in which cell-permeable analogs of ceramide and dihydroceramide were exogenously added to cultured cells [11], indicated for the first time that the double bond is not only required for the signaling properties of ceramide, but also for those of sphingosine-1-phosphate (review: [12]). Dihydroceramide desaturase (Des1) knockout mice display decreased body weight, scaly skin, hematological abnormalities, and abnormal liver function, and die at 8 to 10 weeks after birth [13]. As an additional tool to study the function of the 4,5-double bond of sphingolipids, competitive inhibitors of the desaturase have been developed that share a cyclopropene moiety in positions 4 and 5 of the sphingoid backbone [14-18]. Dihydroceramide levels also increase in response to resveratrol treatment [19].

\section{Results and Discussion}

Here, we report on the synthesis of a cyclopropanebearing dihydroceramide derivative that is able to inhibit the introduction of the double bond into the sphingolipids of cultured cells. The dihydroceramide analog (1) (Scheme 1) is structurally very closely related to dihydroceramide and distinguished from it only by the presence of an additional 


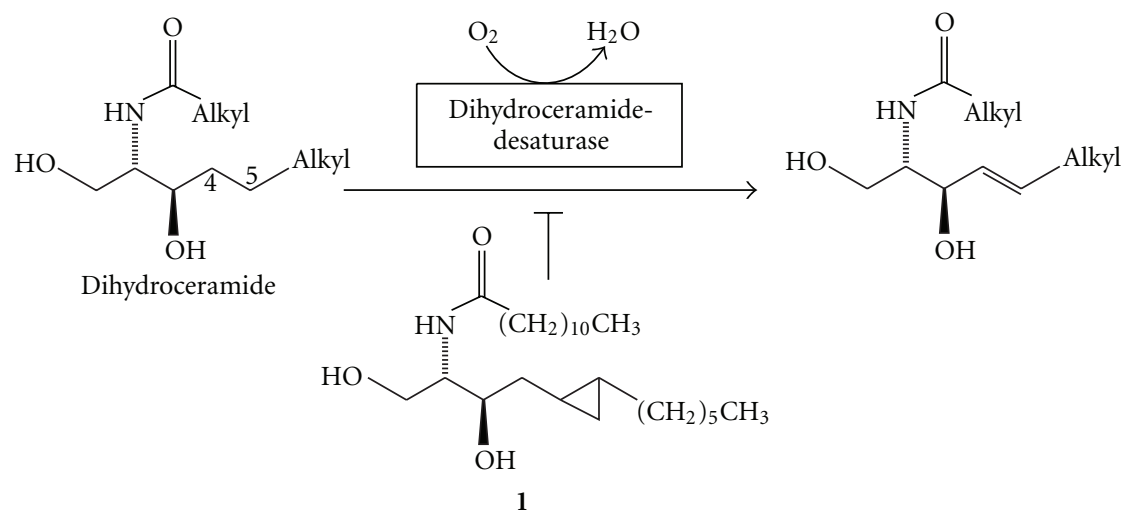

Scheme 1: Enzymatic reaction catalyzed by dihydroceramide desaturase DES1.

methylene group. In addition, the acyl chain is shorter than that of most endogenous ceramides to ensure sufficient cell permeability. Since exogenously added short-chain ceramides are converted in cells into those with endogenous acyl chain lengths by deacylation/reacylation [20], the title compound can behave as the inhibitor or also as the prodrug of a cyclopropanated dihydroceramide of native acyl chain length. In vitro, the desaturase shows optimal activity towards substrates with acyl chain lengths of eight carbon atoms [4], and also inhibition by the cyclopropene-based inhibitor is optimal with this chain length [15]. However, nothing is known about the chain length that is actually optimal in cells. The rationale behind the synthesis of the title compound was that enzyme-catalyzed homolytic cleavage of the C4-H bond within the sphingoid scaffold of 1 and subsequent opening of the cyclopropyl ring should lead to a delocalized radical intermediate that might covalently bind to and in this way inactivate the desaturase. Mechanismbased inhibition of oxidizing enzymes by cyclopropylcontaining substrate analogs has been described before, for example, [21].

The synthesis of $\mathbf{1}$ (Scheme 2) started from Garner's serine aldehyde (2) [22], which was transformed into 3 by a Wittig olefination. Treatment of 3 with metachloroperbenzoic acid led to a $2.8: 1$ diastereomeric mixture of erythro- and threo-epoxides. Pure erythro-epoxide (4) was isolated after flash chromatography and elongated with lithiated octyne to $\mathbf{5}$.

The relative configuration of the carbon atoms C2 and C3 of erythro-5 was determined after selective cleavage of the acetal moiety with Amberlyst 15 in methanol at room temperature and subsequent formation of the 1,3isopropylidene acetal [23]. ${ }^{1} \mathrm{HNMR}$ analysis showed a coupling constant ${ }^{3} \mathrm{~J}_{(4,5)}$ of $9.5 \mathrm{~Hz}$, which confirmed the trans-diaxial relationship of $\mathrm{H}-4$ and $\mathrm{H}-5$ (Scheme 3). The threo-diastereomer had a ${ }^{3} \mathrm{~J}_{(4,5)}$ coupling constant of about $1 \mathrm{~Hz}$.

After acid deprotection of erythro-5 (Scheme 2), the homopropargylic alcohol (6) was reduced to the homoallylalcohol (7) with lithium aluminium hydride. Acylation with lauroyl chloride afforded $\mathbf{8}$. Subsequent introduction of the cyclopropane moiety by the Furukawa variant of the
Simmons-Smith reaction [24] led to two diastereomers of $\mathbf{1}$, which could not be separated.

Since (dihydro)ceramide analogs exogenously added to cultured cells undergo similar metabolic reactions as endogenous ceramides [25], the rapid conversion of $\mathbf{1}$ by ceramide metabolizing enzymes and termination of its effect on the desaturase system had to be expected. Compared to other tissues, the human skin is particularly rich in ceramides [2628]. Therefore, in this cell type, sufficiently high steady-stateconcentrations of $\mathbf{1}$ or of a derivative of $\mathbf{1}$ generated by de- and reacylation with endogenous fatty acids could be expected to prevent the introduction of the double bond. Moreover, a cell culture model of the human skin is available and allows the analysis of markers of differentiation and proliferation, which should be affected by the presence of sphingolipids with and without 4,5-(E)-double bond. For these reasons we investigated $\mathbf{1}$ in cultured differentiated human keratinocytes [29]. After seven days of differentiation, the cells were incubated with different concentrations of $\mathbf{1}$ in the culture medium for 24 hours. The differentiated keratinocytes were then metabolically labeled with L-[3${ }^{14} \mathrm{C}$ ] serine, the biosynthetic precursor of sphingolipids, for 72 hours. Lipids were extracted, separated by thin layer chromatography on silica gel plates impregnated with sodium borate [30], visualized by phosphoimager analysis, and quantified (Figure 1).

The analysis revealed a concentration-dependent decrease of $\mathrm{L}-\left[3-{ }^{14} \mathrm{C}\right]$ serine incorporation into ceramide. $50 \mu \mathrm{M}$ concentration of $\mathbf{1}$ in the culture medium led to a reduction of ceramide labeling to less than $20 \%$ of untreated cells. Dihydroceramide labeling was increased 3.6-fold, and labeling of phytoceramide, which is formed by 4-hydroxylation of dihydroceramide (the accumulated desaturase substrate), was 6.3 -fold elevated compared to untreated cells. In contrast to the title compound $\mathbf{1}$, the cyclopropene-containing inhibitor GT11 [14] did not lead to an elevation of phytoceramide labeling (Bernadette Breiden, personal communication). The effect of 1 on dihydroceramide and ceramide biosynthesis as determined by L-3$\left[{ }^{14} \mathrm{C}\right]$ serine labeling was confirmed with $N-\left[1-{ }^{14} \mathrm{C}\right]$ octanoylsphinganine, which is a cell-permeable analog of dihydroceramide. Also labeling of the ceramide subspecies Cer(AS), 


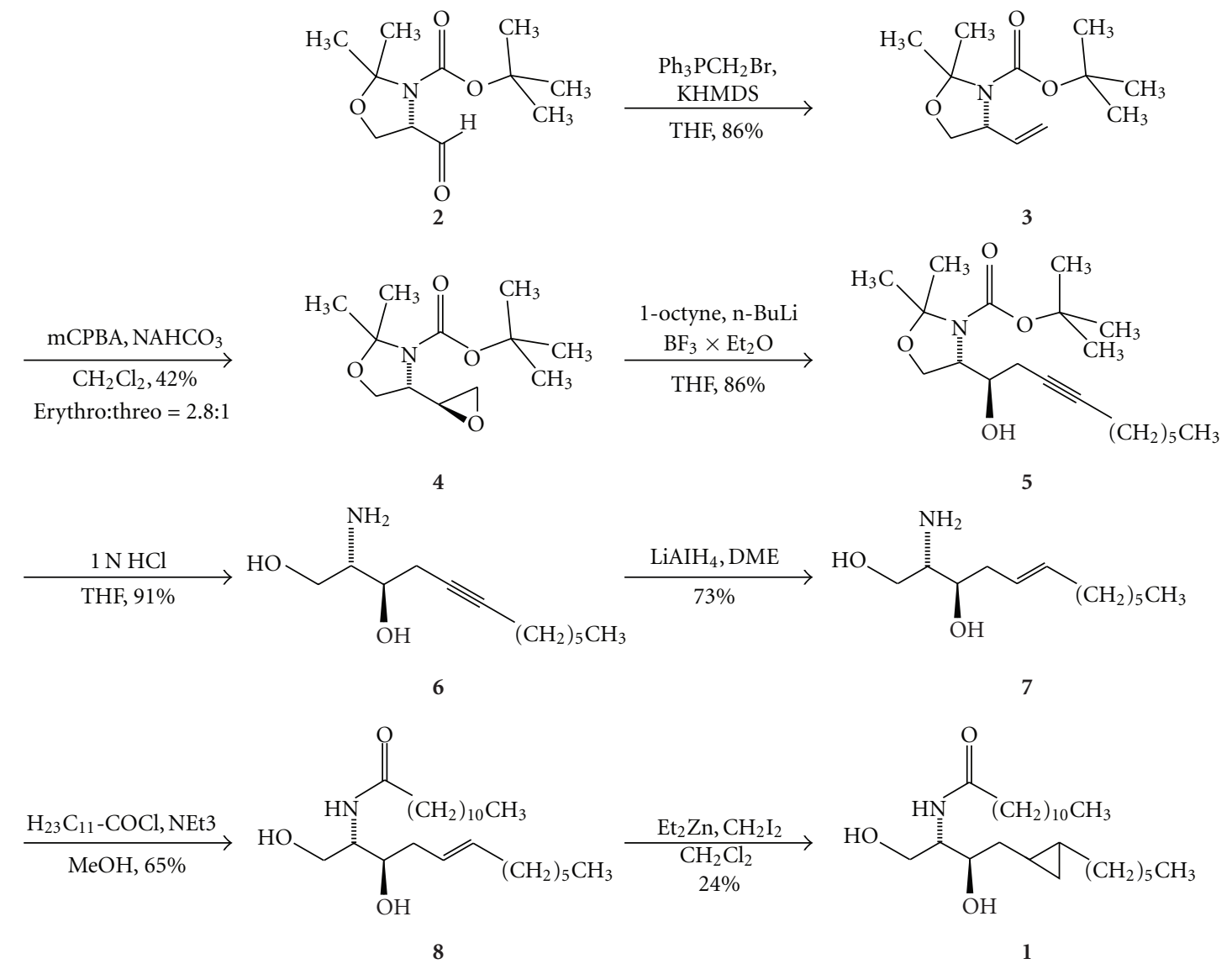

Scheme 2: Reagents and conditions: (a) $\mathrm{Ph}_{3} \mathrm{PCH}_{3} \mathrm{Br}$, KHMDS, THF, $-78^{\circ} \mathrm{C}$ then $\mathrm{rt}, 2 \mathrm{~h}(86 \%)$; (b) $\mathrm{mCPBA}, 0.5 \mathrm{M} \mathrm{NaHCO}_{3}, \mathrm{CH}_{2} \mathrm{Cl}_{2}, 0^{\circ} \mathrm{C}$ then $\mathrm{rt}, 18 \mathrm{~h}(42 \%$, erythro:threo $=2.8: 1)$; (c) 1-octyne, $\mathrm{n}-\mathrm{BuLi}, \mathrm{BF}_{3} \times \mathrm{Et}_{2} \mathrm{O}, \mathrm{THF},-78^{\circ} \mathrm{C}, 30 \mathrm{~min}(86 \%) ;(\mathrm{d}) 1 \mathrm{~N} \mathrm{HCl}, \mathrm{THF}, 70^{\circ} \mathrm{C}, 18 \mathrm{~h}$ (91\%); (e) $\mathrm{LiAlH}_{4}, \mathrm{DME}, 90^{\circ} \mathrm{C}, 12 \mathrm{~h}(73 \%)$; (f) $\mathrm{H}_{23} \mathrm{C}_{11} \mathrm{COCl}, \mathrm{NEt}_{3}, \mathrm{MeOH}, 0^{\circ} \mathrm{C}$ then rt, $18 \mathrm{~h}(65 \%) ;(\mathrm{g}) \mathrm{Et}_{2} \mathrm{Zn}_{2} \mathrm{CH}_{2} \mathrm{I}_{2}, \mathrm{CH}_{2} \mathrm{Cl}_{2}, \mathrm{rt}, 24 \mathrm{~h}$ $(24 \%)$.

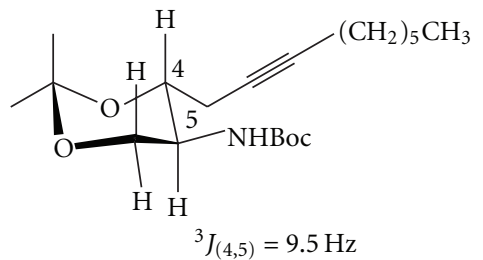

SCHEME 3

which consists of sphingosine acylated with a 2-hydroxy-fatty acid, was reduced. Moreover, labeling of ceramides composed of 2-hydroxyfatty acids and hydroxylated sphingoid bases $(\mathrm{Cer}(\mathrm{AP})$ and $\operatorname{Cer}(\mathrm{AH}))$ was enhanced in the presence of 1 (data not shown). In agreement with the proposed mechanism of action of the title compound, corresponding dihydroceramides with cyclopropane moieties between $\mathrm{C} 4$ and $\mathrm{C} 5$, as well as between $\mathrm{C} 6$ and $\mathrm{C} 7$ of the sphinganine backbone, were inactive (unpublished), although competitive inhibition had to be expected.

Since desaturation and hydroxylation of dihydroceramide should follow a similar mechanism, it is remarkable that 1 leads to an accumulation of dihydroceramide and

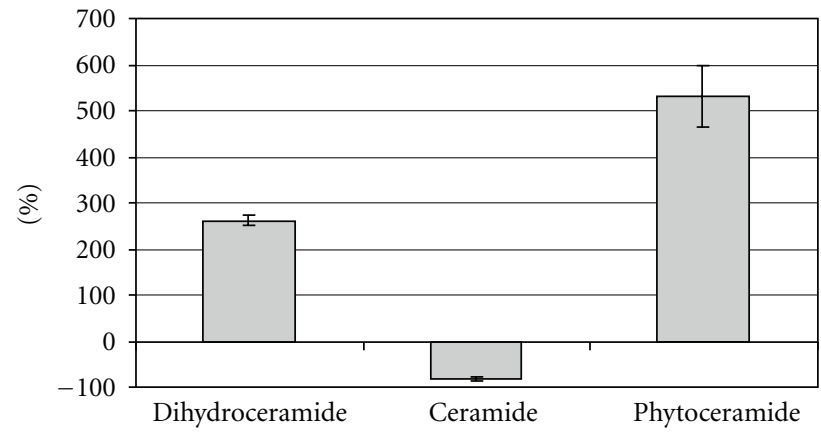

FIGURE 1: Incorporation of $\mathrm{L}-\left[3-{ }^{14} \mathrm{C}\right]$ serine into ceramides of differentiated keratinocytes in the presence of $50 \mu \mathrm{M}$ of 1 . Deviations [\%] from levels obtained in untreated cells, which were cultured as previously described [29], are shown.

phytoceramide on the expense of ceramide levels. The keratinocyte-specific disruption of the gene encoding the transcription factor Arnt in mice led to severe transepidermal water loss because of low levels of both, ceramides and phytoceramides, and elevated concentrations of dihydroceramide in the animals' epidermis [31]. Enzymes with 
both sphingolipid 4-desaturase and 4-hydroxylase activity have been suggested to exist in mice [32, 33] and Candida albicans [34]. Furthermore, a human homolog of the mouse 4-desaturase/4-hydroxylase has been described. Its mRNA expression was shown to be induced during ascorbate/serum-induced differentiation of human keratinocytes [35].

In order to investigate functional consequences of the reduction of newly biosynthesized unsaturated sphingolipids brought about by $\mathbf{1}$, we quantified the mRNA levels of several proteins involved in cell differentiation and ceramide metabolism by real-time polymerase chain reaction (Figure 2 ).

For this purpose, proliferating human keratinocytes were preincubated with 1 for 24 hours. Differentiation was then induced by submitting the cells to an increased calcium ion concentration in the medium, the so-called calcium shift [29]. Former studies already demonstrated a correlation between mRNA and protein levels under these conditions [36].

Figure 2 shows that 24 hours after the onset of the calcium shift, the transcription levels of the suprabasal differentiation marker genes [37], keratin 10 and profilaggrin, were about 95\% lower in cells treated with $\mathbf{1}$ than in untreated cells at the same point of time. On the other hand, the transcription level of the basal marker gene [36], keratin 14, was 40-fold elevated. These expression patterns suggest that treatment with 1 causes an impairment of differentiation, so that the cells remain in a basal proliferative state. The most likely explanation is to attribute this effect to the lack of newly synthesized sphingolipids with 4,5-double bond.

We also determined the mRNA expression of several enzymes involved in ceramide metabolism (Figure 2). The mRNA level of subunit 2 of serine palmitoyl transferase, the enzyme catalyzing the rate-determining step of sphingolipid de novo synthesis, increased more than 70 -fold within 48 hours after the onset of incubation with 1 , whereas the expression in untreated keratinocytes remained low. Also, the transcription levels of glucosylceramide- $\beta$-glucosidase (not shown) and of acid sphingomyelinase, which produce ceramide by the breakdown of glucosylceramide and sphingomyelin, respectively, were upregulated by $\mathbf{1}$ compared to control cells. Unexpectedly, the cells respond to an exogenously added excess of a ceramide analog with an upregulation of proteins required for ceramide formation. However, also the transcription of the gene encoding acid ceramidase that cleaves ceramide into sphingosine and fatty acid was upregulated. These results suggest that increased concentrations of saturated sphingolipids direct sphingolipid metabolism to the production of sphingosine, which can then be phosphorylated to sphingosine-1-phosphate. In contrast to ceramide, sphingosine-1-phosphate behaves as a stimulator of proliferation in most cell types [12]. This again indicates that the 4,5-double bond is required for keratinocyte differentiation, which is disturbed by the accumulation of ceramides saturated within the sphingoid moiety.

Furthermore, we identified several metabolites of $\mathbf{1}$ produced by ceramide metabolizing enzymes within the cell. The analysis was done by electrospray ionization mass
TABLe 1: $N$-acyl metabolites of 1 identified by ESI-MS in lipid extracts of differentiated keratinocytes.

\begin{tabular}{lc}
\hline Fatty acid type & $m / z$ of molecular ion $[\mathrm{M}+\mathrm{H}]^{+}$ \\
\hline $14: 0$ & 440.4 \\
$16: 0$ & 468.4 \\
$16: 0 \mathrm{~h}^{\mathrm{a}}$ & 484.4 \\
$18: 0$ & 496.4 \\
$18: 1$ & 494.4 \\
$22: 0$ & 552.4 \\
$24: 1$ & 578.5 \\
$26: 0$ & 608.5 \\
$28: 1$ & 634.5 \\
\hline
\end{tabular}

${ }^{a} \alpha$-hydroxy fatty acid.

spectrometry (ESI-MS) in lipid extracts of differentiated keratinocytes treated with $\mathbf{1}$. In this way, $N$-acyl metabolites of 1 , produced by ceramidase-catalyzed cleavage of the amide bond and subsequent acylation with different endogenous fatty acids, were found (Table 1). As an example, Figure 3 shows the MS/MS spectrum of the metabolite of 1 acylated by nervonic acid. In addition, the sphingomyelin analog of $\mathbf{1}$, but not the corresponding glucosylated metabolite, could also be identified.

In summary, we demonstrated that addition of nontoxic concentrations of the dihydroceramide analogue $\mathbf{1}$ to cultured keratinocytes reduces the introduction of the double bond into newly synthesized sphingolipids and leads to an impairment of differentiation. As a result, the keratinocytes remain in a basal proliferative state. This indicates that the double bond within the sphingoid moiety of sphingolipids is important for the maintenance of differentiation.

Despite the apparent similarity between the title compound and the family of cyclopropene-based dihydroceramide desaturase inhibitors, there are principle differences between both approaches: cyclopropenes display significant chemical reactivity towards nucleophiles and behave as alkylating agents. Cyclopropene-containing fatty acid analogs interfere with desaturation by addition to thiol groups of cysteine residues [38]. Alkyl cyclopropanes, on the other hand, require oxidation or hydrogen abstraction in $\alpha$-position for reactivity. The cyclopropene inhibitors [14-17] are potent and selective dihydroceramide desaturase inhibitors and have been applied, for example, to analyze the function of dihydrosphingolipids [39]. The best characterized parent compound is a competitive inhibitor with a $K_{i}$ value of $6 \mu \mathrm{M}$ [14]. Side effects, which occur at concentrations above $5 \mu \mathrm{M}$, such as inhibition of serine palmitoyl transferase and accumulation of sphingoid-1-phosphates, have been investigated in neurons [18]. We add information on the new title compound and demonstrate its effect on differentiation and proliferation of cultured human keratinocytes. Since low-molecular weight sphingolipid analogs are discussed as tools for the control of signaling and disease [40], the title compound with only a minimal change in the dihydroceramide structure might be of value for the controlled alteration of cellular properties. 


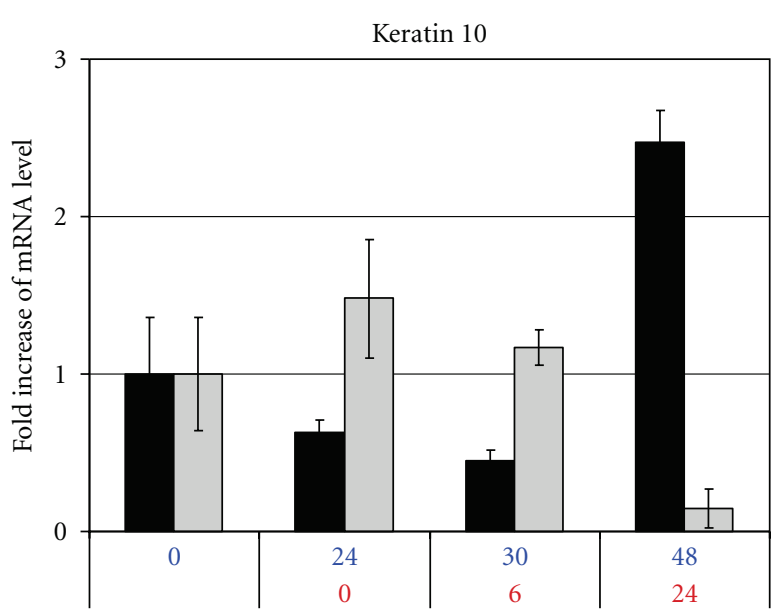

Time after onset of incubation with (1)/of calcium shift (hours)

(a)

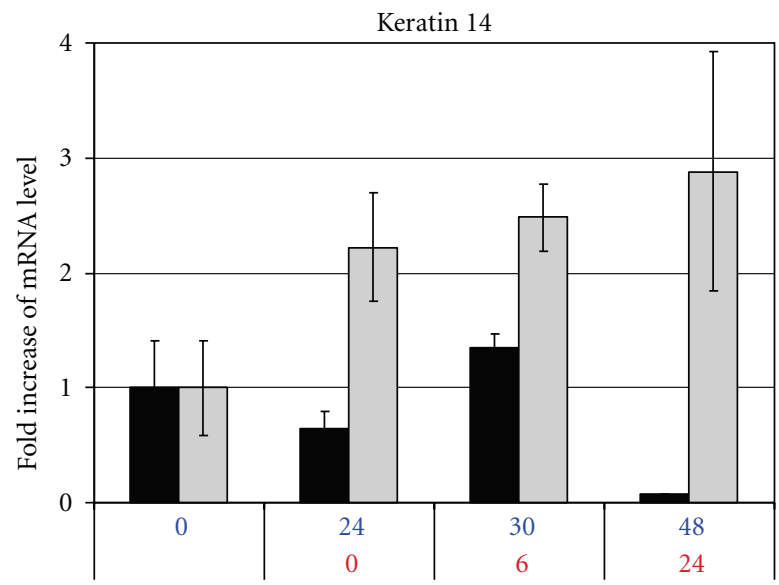

Time after onset of incubation with (1)/of calcium shift (hours)

(c)

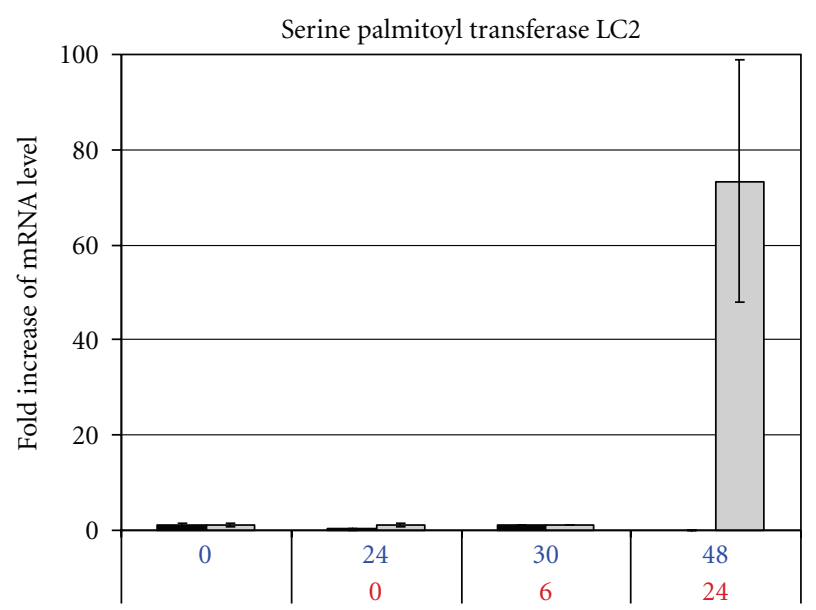

Time after onset of incubation with (1)/of calcium shift (hours)

Untreated control

$50 \mu \mathrm{M}(1)$

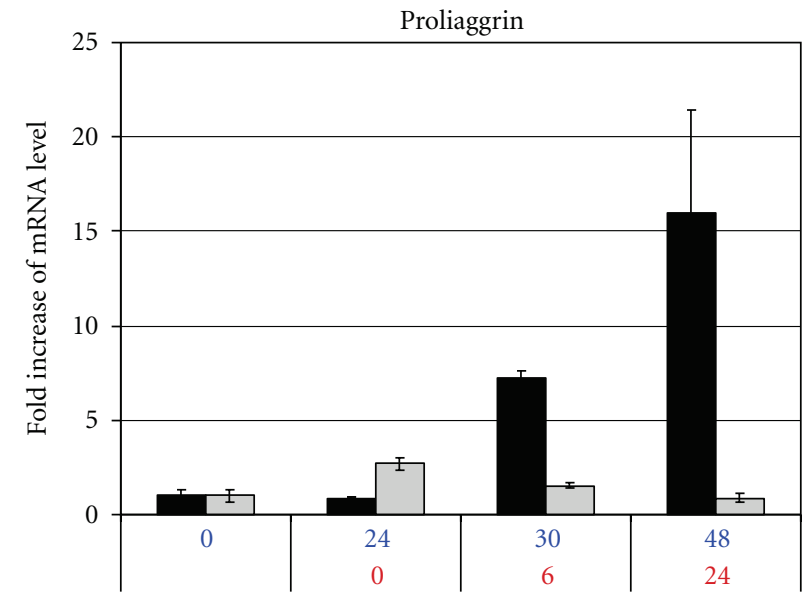

Time after onset of incubation with (1)/of calcium shift (hours)

(b)

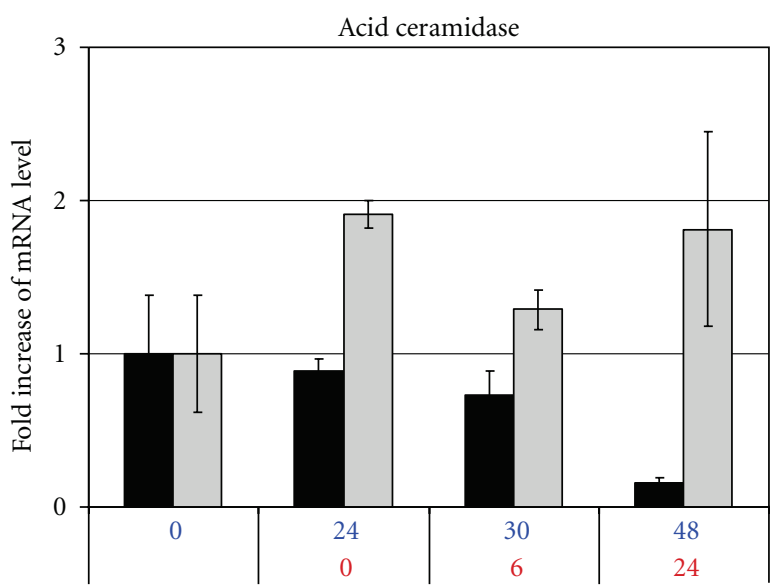

Time after onset of incubation with (1)/of calcium shift (hours)

(d)

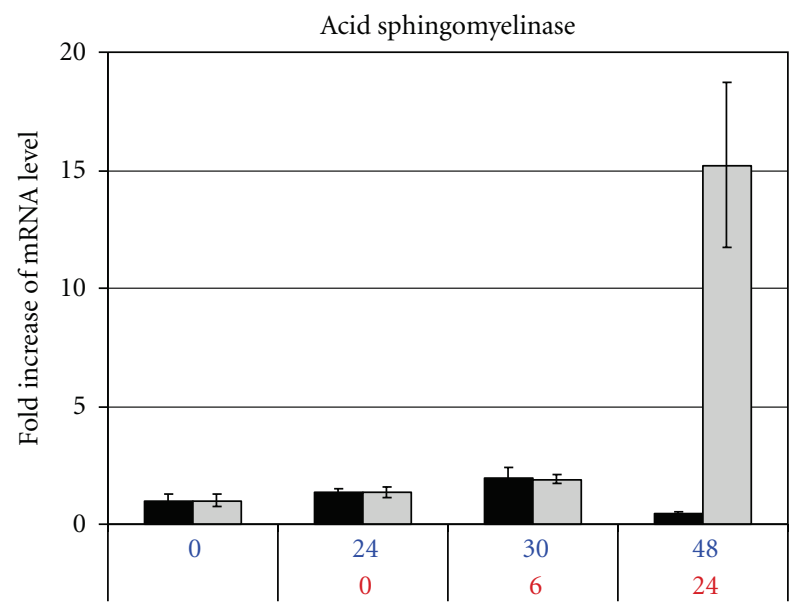

Time after onset of incubation with (1)/of calcium shift (hours)

Untreated control

$50 \mu \mathrm{M}(1)$

(e)

FIGURE 2: Effect of 1 on transcription levels of differentiation markers and enzymes of sphingolipid metabolism in cultured human keratinocytes. Proliferating cells were incubated with $50 \mu \mathrm{M}$ of $\mathbf{1}$ for $24 \mathrm{~h}$ and were then submitted to a calcium shift to induce differentiation. 


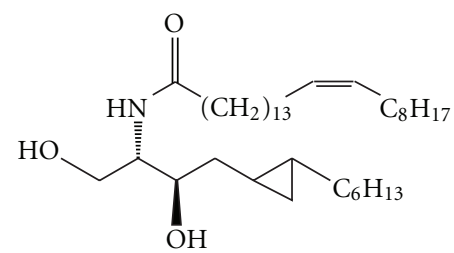

$[\mathrm{M}]: \mathrm{m} / z=577.54$

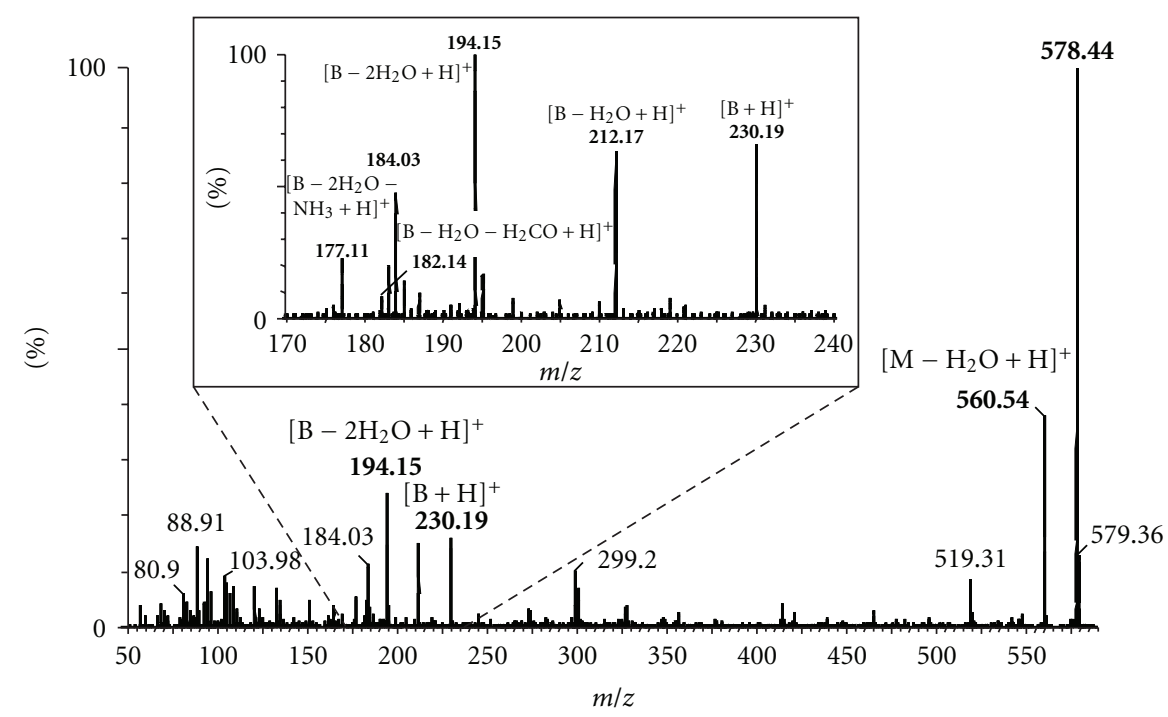

FIGURE 3: MS/MS spectrum of the metabolite of 1 acylated with nervonic acid ( $\mathrm{B}=$ sphingoid base).

\section{Experimental}

3.1. Analytical Data. $N-\left((1 S, 2 R)-\left(3-\left(2^{\prime}-\right.\right.\right.$ Hexylcyclopropyl)2-hydroxy-1-hydroymethyl-propyl)) dodecanamide (1): $\mathrm{R}_{\mathrm{f}}$ (chloroform/methanol 20:1) $=0.23$.

${ }^{1} \mathrm{H}-\mathrm{NMR}\left(300 \mathrm{MHz}, \mathrm{CDCl}_{3}\right): \delta=0.15-0.31(\mathrm{~m}, \mathrm{br}$, $2 \mathrm{H}$, cyclopropyl-H), $0.36-0.55$ (m, br, $2 \mathrm{H}$, cyclopropyl$\mathrm{H}), 0.86\left(\mathrm{t}, \mathrm{J}=6.5 \mathrm{~Hz}, 6 \mathrm{H}, \mathrm{CH}_{3}\right), 1.13-1.41(\mathrm{~m}, 28 \mathrm{H}$, $\left.\mathrm{CH}_{2}\right), 1.41-1.50(\mathrm{~m}, \mathrm{br}, 1 \mathrm{H}$, cyclopropyl-H), $1.62(\mathrm{~m}$, $\left.2 \mathrm{H}, \mathrm{CH}_{2}\right), 2.21\left(\mathrm{t}, \mathrm{J}=7.5 \mathrm{~Hz}, 2 \mathrm{H}, \mathrm{CH}_{2} \mathrm{CO}\right), 2.50-2.85(\mathrm{~m}$, br, $\left.2 \mathrm{H}, \mathrm{HOCH}_{2}, 2-\mathrm{OH}\right), 3.69(\mathrm{dd}, \mathrm{J}=11.0 \mathrm{~Hz}, \mathrm{~J}=3.0 \mathrm{~Hz}$, $\left.1 \mathrm{H}, \mathrm{HOCH}_{\mathrm{A}} \mathrm{H}_{\mathrm{B}}\right), 3.81-3.90$ (m, br, 2H, 1-H, 2-H), $3.95\left(\mathrm{dd}, \mathrm{J}=11.0 \mathrm{~Hz}, \mathrm{~J}=3.0 \mathrm{~Hz}, 1 \mathrm{H}, \mathrm{HOCH}_{\mathrm{A}} H_{\mathrm{B}}\right), 6.36(\mathrm{~d}$, $\mathrm{J}=7.0 \mathrm{~Hz}, 1 \mathrm{H}, \mathrm{NH}) .{ }^{13} \mathrm{C}-\mathrm{NMR}\left(75 \mathrm{MHz}, \mathrm{CDCl}_{3}\right): \delta=11.2$ (11.9) (cyclopropyl-C), $14.1\left(\mathrm{CH}_{3}\right), 15.1$ (15.2) (cyclopropylC), 18.1 (19.1) (cyclopropyl-C), $22.7-34.0\left(\mathrm{CH}_{2}\right), 36.9$ $\left(\mathrm{CH}_{2} \mathrm{CO}\right), 38.9$ (3-C), $53.6(1-\mathrm{C}), 62.4\left(\mathrm{HOCH}_{2}\right), 74.8$ (2-C), 173.6 (CO). The signal duplication for the carbon atoms of the cyclopropane ring in 5,6-position of the dihydroceramide scaffold can be attributed to the formation of two diastereomers with different configuration during the Simmons-Smith reaction.

FAB-MS (mNBA, $\left.\mathrm{C}_{25} \mathrm{H}_{49} \mathrm{NO}_{3}\right): m / z=412[\mathrm{M}+\mathrm{H}]^{+}$, $450[\mathrm{M}+\mathrm{K}]^{+}$; EI-MS (HR-MS): calcd.: 411,3712, found: 411,3711 .

Cell culture experiments and quantification of mRNA levels via real-time quantitative PCR were performed according to [36].
3.2. Cell Culture. Human foreskin keratinocytes were cultivated according to a modified Rheinwald and Green method [36] and grown to confluence in low calcium (0.1 mM) MCDB-153 medium. Differentiation was initiated by elevating the calcium ion concentrations to $1.1 \mathrm{mM}$ ("calcium shift") and addition of linoleic acid/BSA $(10 \mu \mathrm{M})$ to the MCDB-153 medium. In the presence of inhibitor 1, cells were viable as determined by morphology, cell protein content, and metabolic capability to incorporate radiolabeled serine into sphingolipids, when compared to untreated cells.

3.3. Ceramide Labeling. After 8 days of calcium shift, the medium was replaced by the corresponding serine-deficient medium and $\mathrm{L}-\left[3-{ }^{14} \mathrm{C}\right]$ serine was added $(1 \mu \mathrm{Ci} / \mathrm{mL}$ medium $)$ after one hour. Cells were harvested 72 hours after the addition of radiolabeled serine. 1 was dissolved in ethanol ( $10 \mathrm{mM}$ solution) and added to the cell culture medium 24 hours before labeling. All cell culture experiments were conducted at least in duplicate.

3.4. Lipid Extraction and Analysis. Cells were harvested and then homogenized by sonication in water. Lipids were extracted by addition of methanol and chloroform and subsequent incubation at $37^{\circ}$ for $24 \mathrm{~h}$. Lipid extracts were desalted on LiChroprep RP-18 columns, and the incorporated radioactivity was quantified by liquid scintillation counting (Packard Instruments, Tri-Carb 1600 TR). In order 
to quantify the relative distribution of radioactivity within the different ceramide subspecies, TLC separation using the solvent systems chloroform/methanol 9:1 (v/v) on borateimpregnated silica gel plates and phosphoimager analysis (Fuji, Fujix BAS 1000) were performed. Ceramide (Cer(NS)), dihydroceramide (Cer(ND)), and phytoceramide (Cer(NP)) were clearly separated by this method. To separate ceramide subspecies, Cer(NS) and Cer(ND), from those acylated with 2-hydroxy-fatty acids (Cer(AS), Cer(AP), and $\operatorname{Cer}(\mathrm{AH})$ ), TLCs were run twice in chloroform/methanol/acetic acid $190: 9: 1(\mathrm{v} / \mathrm{v} / \mathrm{v})$. Lipids were identified by comparing their mobility with authentic reference standards.

\subsection{Electrospray Ionization-Time of Flight-Mass Spectrome-} try. Measurements were conducted on a Q-ToF-2 Hybrid Quadrupole-mass spectrometer with nanoflow interface (Micromass) in positive or negative ion mode. Lipid extracts were evaporated in a stream of nitrogen, dissolved in Chloroform/Methanol 1:1 (v/v), and sonicated for five minutes. For the suppression of sodium adducts, the sample was mixed with an aqueous solution of $1 \mathrm{M}$ ammonium acetate to a final concentration of $50 \mathrm{mM}$. The sample was vortexed and centrifuged. $5 \mu \mathrm{L}$ of the supernatant were applied to precoated glass capillaries and measured at a source temperature of $80^{\circ} \mathrm{C}$, a capillary voltage of $900-1000 \mathrm{~V}$, and a cone voltage of $50 \mathrm{~V}$. Calibration was performed using sodium iodide $(2 \mathrm{mg} / \mathrm{mL})$ and cesium iodide $(0.05 \mathrm{mg} / \mathrm{mL})$ in 1-propanol/water $1: 1(\mathrm{v} / \mathrm{v})$. MS/MS spectra were recorded with argon as collision gas at an argon partial pressure of 0.7 bar. Collision energies were in the range of 30 to $40 \mathrm{eV}$.

3.6. RNA Extraction and Quantification. In order to investigate the effect of $\mathbf{1}$ on the differentiation of human keratinocytes, the cells were grown to confluence as described above. 24 hours before the onset of calcium shift, 1 was added to the cell culture for preincubation. The cells were harvested after the indicated periods of time (see Figure 2), and total RNA was extracted using the Purescript RNA isolation kit according to the supplier's instructions. RNA quality was tested using a 1.2\% standard RNA agarose gel and by measuring the optical density ratio $\mathrm{A}_{260} / \mathrm{A}_{280}(\geq 2.0)$. RNA solutions were then diluted to $25 \mathrm{ng} / \mu \mathrm{l}$ in sterile water treated with diethyl pyrocarbonate (DEPC) and stored at $-80^{\circ} \mathrm{C}$.

3.7. Real-Time PCR RNA Quantification. For every gene studied, primers were dissolved in DEPC-treated sterile water. All fluorogenic probes contained the reporter dye FAM covalently attached to the $5^{\prime}$-end and the quencher dye TAMRA covalently attached to the $3^{\prime}$-end. Extension from the $3^{\prime}$-end was blocked by attachment of a $3^{\prime}$-phosphate group.

3.8. cDNA Synthesis. The target RNA (75 ng) was reversetranscribed using the MuLV reverse transcriptase (Applied Biosystems) at $48^{\circ} \mathrm{C}$ for $30 \mathrm{~min}$. The total reaction volume was $20 \mu \mathrm{L}$. After cDNA synthesis, reverse transcriptase was denatured at $95^{\circ} \mathrm{C}$ for $10 \mathrm{~min}$.
3.9. PCR Amplification. PCR reactions were performed with the ABI Prism 7700 sequence detection system (Applied Biosystems). $20 \mu \mathrm{l}$ of the RT-PCR reaction from each cDNA sample were amplified using the AmpliTaq Gold (Applied Biosystems) in a total volume of $90 \mu \mathrm{l}$. Each amplification was performed in triplicate under the following conditions: $2 \mathrm{~min}$ at $50^{\circ} \mathrm{C}$ and $10 \mathrm{~min}$ at $95^{\circ} \mathrm{C}$, followed by a total of 45 two-step cycles $\left(15 \mathrm{~s}\right.$ at $95^{\circ} \mathrm{C}$ and $1 \mathrm{~min}$ at $60^{\circ} \mathrm{C}$ ). As an endogenous control, the porphobilinogen deaminase (PBGD) gene mRNA was used, which was quantified in parallel. The results were analyzed utilizing the standard curve method as described in User Bulletin number 2 (ABI Prism 7700 sequence detection system, Applied Biosytems).

\section{Abbreviations}

For nomenclature of epidermal ceramides, compare [26] or [27]: N: non-hydroxy-fatty acid; A: $\alpha$-hydroxy-fatty acid; S: sphingosine; P: phytosphingosine; H: 6-hydroxysphingosine; D: dihydrosphingosine (sphinganine).

\section{Acknowledgments}

The authors thank Professor Dr. K. Sandhoff, Dr. B. Breiden, and Dr. H. Gallala for helpful discussions. This work was supported by the Deutsche Forschungsgemeinschaft and the European Community (7th framework program "LipidomicNet," Proposal no. 202272).

\section{References}

[1] N. Bartke and Y. A. Hannun, "Bioactive sphingolipids: metabolism and function," Journal of Lipid Research, vol. 50, pp. S91-96, 2009.

[2] T. Wennekes, R. J. B. H. N. van den Berg, R. G. Boot, G. A. van der Marel, H. S. Overkleeft, and J. M. F. G. Aerts, "Glycosphingolipids-nature, function, and pharmacological modulation," Angewandte Chemie - International Edition, vol. 48, no. 47, pp. 8848-8869, 2009.

[3] A. Delgado, J. Casas, A. Llebaria, J. L. Abad, and G. Fabriás, "Chemical tools to investigate sphingolipid metabolism and functions," ChemMedChem, vol. 2, no. 5, pp. 580-606, 2007.

[4] C. Michel, G. van Echten-Deckert, J. Rother, K. Sandhoff, E. Wang, and A. H. Merrill Jr., "Characterization of ceramide synthesis. A dihydroceramide desaturase introduces the 4,5trans-double bond of sphingosine at the level of dihydroceramide," The Journal of Biological Chemistry, vol. 272, no. 36, pp. 22432-22437, 1997.

[5] L. Geeraert, G. P. Mannaerts, and P. P. van Veldhoven, "Conversion of dihydroceramide into ceramide: involvement of a desaturase," Biochemical Journal, vol. 327, no. 1, pp. 125$132,1997$.

[6] C. Michel and G. van Echten-Deckert, "Conversion of dihydroceramide to ceramide occurs at the cytosolic face of the endoplasmic reticulum," FEBS Letters, vol. 416, no. 2, pp. 153155, 1997.

[7] T. Mikami, M. Kashiwagi, K. Tsuchihashi, T. Akino, and S. Gasa, "Substrate specificity and some other enzymatic properties of dihydroceramide desaturase (Ceramide synthase) in fetal rat skin," Journal of Biochemistry, vol. 123, no. 5, pp. 906911, 1998. 
[8] E. Beauchamp, D. Goenaga, J. Le Bloc'h, D. Catheline, P. Legrand, and V. Rioux, "Myristic acid increases the activity of dihydroceramide $\Delta 4$-desaturase 1 through its $\mathrm{N}$-terminal myristoylation," Biochimie, vol. 89, no. 12, pp. 1553-1561, 2007.

[9] Y. Mizutani, A. Kihara, and Y. Igarashi, "Identification of the human sphingolipid C4-hydroxylase, hDES2, and its upregulation during keratinocyte differentiation," FEBS Letters, vol. 563, no. 1-3, pp. 93-97, 2004.

[10] C. K. Savile, G. Fabriàs, and P. H. Buist, "Dihydroceramide $\Delta 4$ desaturase initiates substrate oxidation at C-4," Journal of the American Chemical Society, vol. 123, no. 19, pp. 4382-4385, 2001.

[11] A. Bielawska, H. M. Crane, D. Liotta, L. M. Obeid, and Y. A. Hannun, "Selectivity of ceramide-mediated biology. Lack of activity of erythro- dihydroceramide," The Journal of Biological Chemistry, vol. 268, no. 35, pp. 26226-26232, 1993.

[12] H. Fyrst and J. D. Saba, "An update on sphingosine-1phosphate and other sphingolipid mediators," Nature Chemical Biology, vol. 6, no. 7, pp. 489-497, 2010.

[13] W. L. Holland, J. T. Brozinick, L.-P. Wang et al., "Inhibition of ceramide synthesis ameliorates glucocorticoid-, saturated-fat, and obesity-induced insulin resistance," Cell Metabolism, vol. 5, no. 3, pp. 167-179, 2007.

[14] G. Triola, G. Fabriàs, and A. Llebaria, "Synthesis of a cyclopropene analogue of ceramide, a potent inhibitor of dihydroceramide desaturase," Angewandte Chemie - International Edition, vol. 40, no. 10, pp. 1960-1962, 2001.

[15] G. Triola, G. Fabriàs, J. Casas, and A. Llebaria, "Synthesis of cyclopropene analogues of ceramide and their effect on dihydroceramide desaturase," Journal of Organic Chemistry, vol. 68, no. 26, pp. 9924-9932, 2003.

[16] C. Bedia, G. Triola, J. Casas, A. Llebaria, and G. Fabriàs, "Analogs of the dihydroceramide desaturase inhibitor GT11 modified at the amide function: synthesis and biological activities," Organic and Biomolecular Chemistry, vol. 3, no. 20, pp. 3707-3712, 2005.

[17] J. M. Munoz-Olaya, X. Matabosch, C. Bedia et al., "Synthesis and biological activity of a novel inhibitor of dihydroceramide desaturase," ChemMedChem, vol. 3, no. 6, pp. 946-953, 2008.

[18] G. Triola, G. Fabrias, M. Dragusin et al., "Specificity of the dihydroceramide desaturase inhibitor N-[(1R,2S)-2-hydroxy1-hydroxymethyl-2-(2-tridecyl-1-cyclopropenyl)ethyl] octanamide (GT11) in primary cultured cerebellar neurons," Molecular Pharmacology, vol. 66, no. 6, pp. 1671-1678, 2004.

[19] P. Signorelli, J. M. Munoz-Olaya, V. Gagliostro, J. Casas, R. Ghidoni, and G. Fabriàs, "Dihydroceramide intracellular increase in response to resveratrol treatment mediates autophagy in gastric cancer cells," Cancer Letters, vol. 282, no. 2, pp. 238-243, 2009.

[20] B. Ogretmen, B. J. Pettus, M. J. Rossi et al., "Biochemical mechanisms of the generation of endogenous long chain ceramide in response to exogenous short chain ceramide in the A549 human lung adenocarcinoma cell line. Role for endogenous ceramide in mediating the action of exogenous ceramide," The Journal of Biological Chemistry, vol. 277, no. 15, pp. 12960-12969, 2002.

[21] R. B. Silverman, C. Z. Ding, J. L. Borrillo, and J. T. Chang, "Mechanism-based enzyme inactivation via a diactivated cyclopropane intermediate," Journal of the American Chemical Society, vol. 115, pp. 2982-2983, 1993.

[22] P. Garner, J. M. Park, and E. Malecki, "A stereodivergent synthesis of D-erythro-sphingosine and D-threo-sphingosine from L-serine," Journal of Organic Chemistry, vol. 53, no. 18, pp. 4395-4398, 1988.

[23] P. Herold, "Synthesis of D-erythro- and D-threo-sphingosine derivatives from L-serine," Helvetica Chimica Acta, vol. 71, no. 2, pp. 354-362, 1988.

[24] J. Furukawa, N. Kawabata, and J. Nishimura, "Synthesis of cyclopropanes by the reaction of olefins with dialkylzinc and methylene iodide," Tetrahedron, vol. 24, no. 1, pp. 53-58, 1968.

[25] G. van Echten-Deckert, A. Giannis, A. Schwarz, A. H. Futerman, and K. Sandhoff, "1-Methylthiodihydroceramide, a novel analog of dihydroceramide, stimulates sphinganine degradation resulting in decreased de novo sphingolipid biosynthesis," The Journal of Biological Chemistry, vol. 273, no. 2, pp. 1184-1191, 1998.

[26] W. M. Holleran, Y. Takagi, and Y. Uchida, "Epidermal sphingolipids: metabolism, function, and roles in skin disorders," FEBS Letters, vol. 580, no. 23, pp. 5456-5466, 2006.

[27] Y. Uchida and W. M. Holleran, "Omega-O-acylceramide, a lipid essential for mammalian survival," Journal of Dermatological Science, vol. 51, no. 2, pp. 77-87, 2008.

[28] Y. Mizutani, S. Mitsutake, K. Tsuji, A. Kihara, and Y. Igarashi, "Ceramide biosynthesis in keratinocyte and its role in skin function," Biochimie, vol. 91, no. 6, pp. 784-790, 2009.

[29] B. Breiden, H. Gallala, T. Doering, and K. Sandhoff, "Optimization of submerged keratinocyte cultures for the synthesis of barrier ceramides," European Journal of Cell Biology, vol. 86, no. 11-12, pp. 657-673, 2007.

[30] K. A. Karlsson and I. Pascher, "Thin-layer chromatography of ceramides," Journal of Lipid Research, vol. 12, no. 4, pp. 466472, 1971.

[31] S. Takagi, H. Tojo, S. Tomita et al., "Alteration of the 4sphingenine scaffolds of ceramides in keratinocyte-specific Arnt-deficient mice affects skin barrier function," The Journal of Clinical Investigation, vol. 112, no. 9, pp. 1372-1382, 2003.

[32] P. Ternes, S. Franke, U. Zähringer, P. Sperling, and E. Heinz, "Identification and characterization of a sphingolipid $\Delta 4$ desaturase family," The Journal of Biological Chemistry, vol. 277, no. 28, pp. 25512-25518, 2002.

[33] F. Omae, M. Miyazaki, A. Enomoto, and A. Suzuki, "Identification of an essential sequence for dihydroceramide C-4 hydroxylase activity of mouse DES2," FEBS Letters, vol. 576, no. 1-2, pp. 63-67, 2004.

[34] C. Beckmann, J. Rattke, P. Sperling, E. Heinz, and W. Boland, "Stereochemistry of a bifunctional dihydroceramide $\delta 4$ - desaturase/hydroxylase from Candida albicans; a key enzyme of sphingolipid metabolism," Organic and Biomolecular Chemistry, vol. 1, no. 14, pp. 2448-2454, 2003.

[35] Y. Mizutani, A. Kihara, and Y. Igarashi, "Identification of the human sphingolipid C4-hydroxylase, hDES2, and its upregulation during keratinocyte differentiation," FEBS Letters, vol. 563, no. 1-3, pp. 93-97, 2004.

[36] H. Gallala, O. Macheleidt, T. Doering, V. Schreiner, and K. Sandhoff, "Nitric oxide regulates synthesis of gene products involved in keratinocyte differentiation and ceramide metabolism," European Journal of Cell Biology, vol. 83, no. 1112, pp. 667-679, 2004.

[37] D. R. Roop, H. Huitfeldt, A. Kilkenny, and S. H. Yuspa, "Regulated expression of differentiation-associated keratins in cultured epidermal cells detected by monospecific antibodies to unique peptides of mouse epidermal keratins," Differentiation, vol. 35, no. 2, pp. 143-150, 1987.

[38] P. K. Raju and R. Reiser, "Inhibition of fatty acyl desaturase by cyclopropene fatty acids," The Journal of Biological Chemistry, vol. 242, no. 3, pp. 379-384, 1967. 
[39] C. R. Vieira, J. M. Munoz-Olaya, J. Sot et al., "Dihydrosphingomyelin impairs HIV-1 infection by rigidifying liquidordered membrane domains," Chemistry and Biology, vol. 17, no. 7, pp. 766-775, 2010.

[40] P. Gangoiti, L. Camacho, L. Arana et al., "Control of metabolism and signaling of simple bioactive sphingolipids: implications in disease," Progress in Lipid Research, vol. 49, no. 4, pp. 316-334, 2010. 

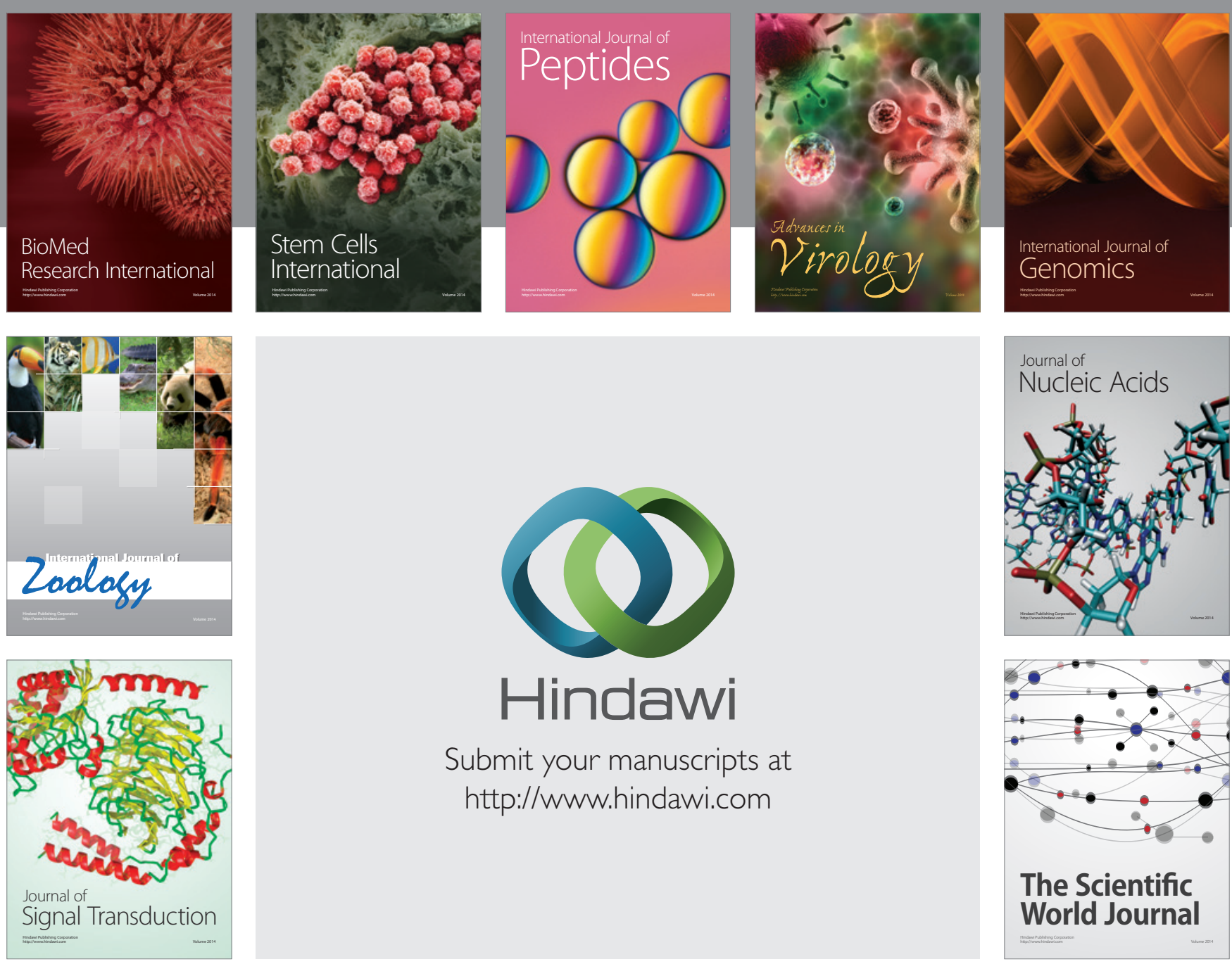

Submit your manuscripts at

http://www.hindawi.com
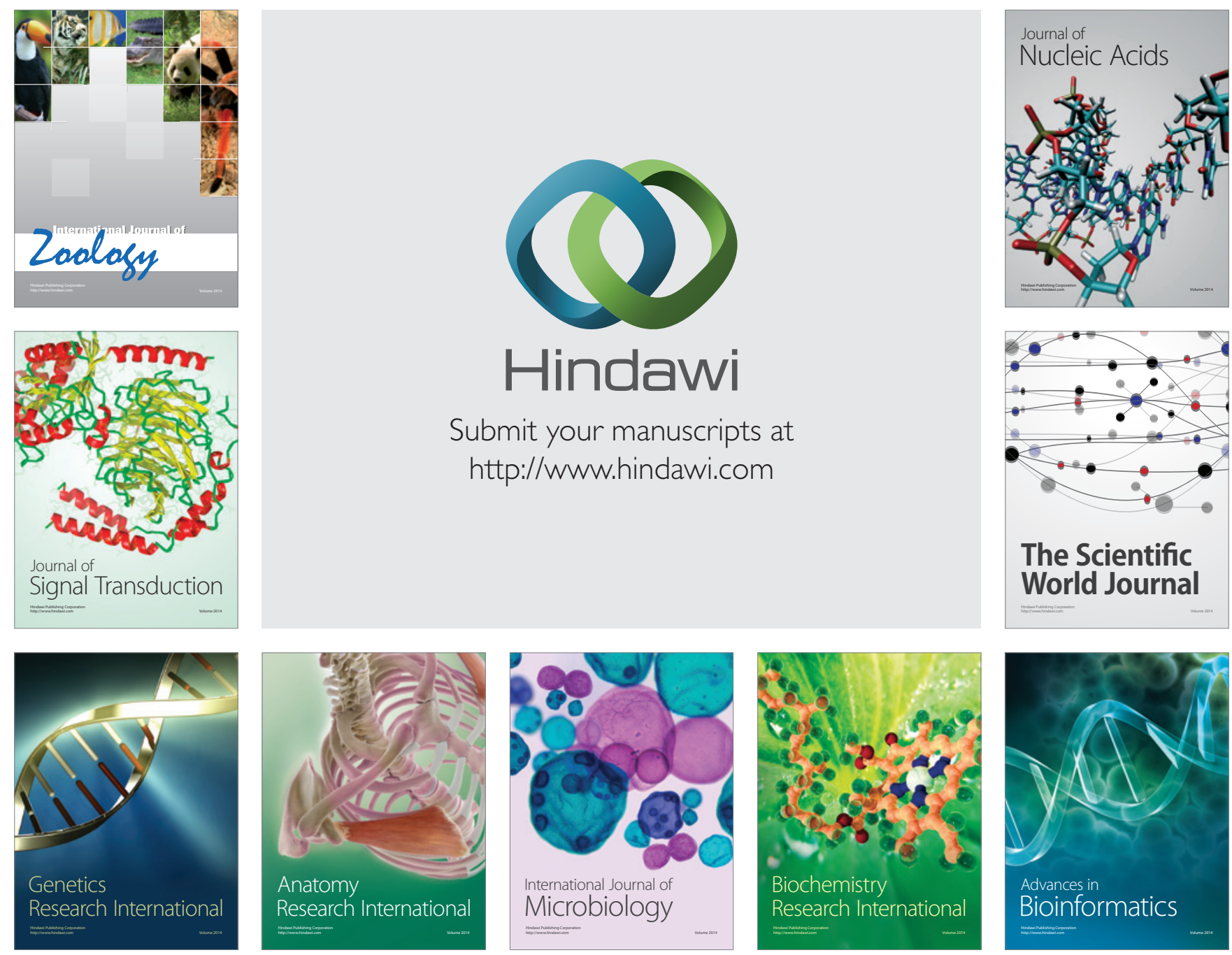

The Scientific World Journal
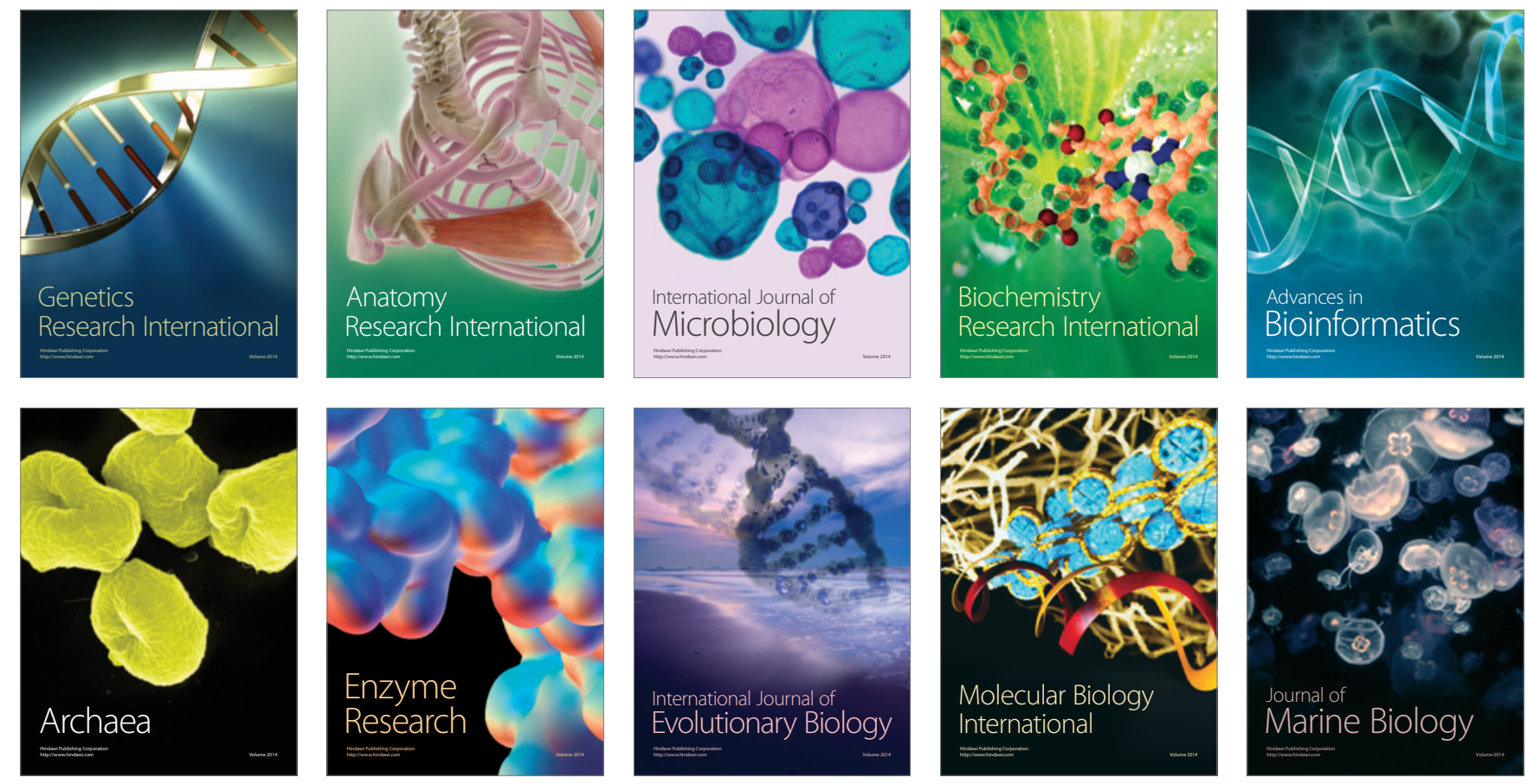